\title{
Predictive Accuracy of Tissue Doppler Imaging for Assessment of Noninfarct Myocardial Region in Patients with Acute Myocardial Infarction
}

\author{
Aly Mohamad Hegazy ${ }^{a} \quad$ Mousa A.J. Akbarc Ali Al-Sayegh ${ }^{d}$ \\ Bader A. Abdulkader ${ }^{\text {b }}$ \\ ${ }^{a}$ Noninvasive Cardiac Laboratory and ${ }^{b}$ Department of Medicine, Farwania Hospital, \\ cCoronary Care Unit, Sabah Hospital, and d Cardiology Department, Chest Diseases Hospital, Kuwait
}

\section{Key Words}

Tissue Doppler imaging • Myocardial infarction •

Coronary angiography

\begin{abstract}
Objectives: To investigate the value of pulsed tissue Doppler imaging (TDI) in order to predict significant coronary artery stenosis supplying the noninfarct region in patients after acute anterior myocardial infarction. Subjects and Methods: Transthoracic echocardiography and coronary angiography were performed on 220 patients with acute anterior myocardial infarction. The TDI-derived variables of the mitral valve annulus in the noninfarct region, systolic velocity $(\mathrm{Sm})$, early diastolic velocity (Em) and late diastolic velocity $(\mathrm{Am})$, were estimated in centimeters per second, and the Em/ Am ratio was calculated. Results: Predictive indices revealed that the impaired TDI-derived variables, Sm, Em, Am and the Em/Am ratio, were an indicator for predicting significant coronary stenosis in the noninfarct region. Multivariate analysis revealed that the impaired $\mathrm{Sm}$ and $\mathrm{Em}$ velocities were significantly associated with age of the patients, coronary collaterals and infarct-related artery stenosis ( $p<0.05$ ). Receiver-operating characteristic curve data of TDI-derived variables for prediction of significant coronary stenosis revealed that the cut-off values of Sm, Em, Am and Em/Am ratio were $7.2 \mathrm{~cm} / \mathrm{s}, 6.4 \mathrm{~cm} / \mathrm{s}, 12.1 \mathrm{~cm} / \mathrm{s}$ and 0.56 , respective-
\end{abstract}

ly. The $к$ coefficient value indicated that there was an agreement between coronary angiography and the TDI-derived variables $\mathrm{Sm}, \mathrm{Em}, \mathrm{Am}$ and $\mathrm{Em} / \mathrm{Am}$ ratio in noninfarct regions ( $\kappa=0.770,0.731,0.693$ and 0.679 , respectively). There was a significant correlation between the severity of coronary artery stenosis (independent variable) and impaired Sm and $\mathrm{Em} / \mathrm{Am}$ ratio (dependent variables), $\mathrm{y}=11.5-0.05 \mathrm{x}$, $r=-0.902,(p<0.05)$, and $y=-0.14 x+1.87, r=-0.754,(p<$ $0.05)$, respectively. Conclusion: TDI can be used to identify patients with significant stenosis of the coronary arteries supplying the noninfarct region and consequently may be helpful in considering patients for coronary angiography in the early postinfarction period.

Copyright $\odot 2007$ S. Karger AG, Basel

\section{Introduction}

Echocardiography has evolved as a well-established tool for the noninvasive evaluation of regional and global myocardial function. However, the existing 2-dimensional (2D) techniques have two important limitations. Firstly, 2D echocardiographic imaging using a gray scale does not always give effective delineation of the endocardial border for a proper evaluation of regional wall motion in a significant subset of patients [1]. Secondly, because analysis of regional wall motion is semiqualitative,

\section{KARGER}

Fax +41613061234

E-Mail karger@karger.ch

www.karger.com
(C) 2007 S. Karger AG, Basel

$1011-7571 / 07 / 0161-0040 \$ 23.50 / 0$

Accessible online at:

www.karger.com/mpp
Dr. Aly Hegazy, MB, BCh, MS, PhD

Noninvasive Cardiac Laboratory, Medicine Department, Farwania Hospital PO Box 18373

Kuwait 81004 (Kuwait)

Tel. +965 488 2379, Fax +965 483 7079, E-Mail alymhd57@hotmail.com 
there is a considerable learning curve and substantial inter- and intraobserver variability as noted by Bountioukos et al. [2]. Therefore, the search for superior techniques to quantify regional and global myocardial function continues.

Tissue Doppler imaging (TDI) is a new ultrasound technique that uses shifts in Doppler frequencies for quantifying myocardial motion [3]. As it does not depend on the amplitude of the reflected wave, it is possible to get information regarding myocardial wall motion from an area that may not have satisfactory gray scale information on 2D echocardiography [4]. Currently, TDI is a useful technique for quantifying the nature and extent of myocardial dysfunction in several diseased states [5]. The aim of the study was to investigate the value of pulsed TDI in predicting significant coronary artery stenosis supplying the noninfarct region.

\section{Subjects and Methods}

\section{Subjects}

Two hundred and twenty patients (200 males and 20 females) with acute anterior myocardial infarction were included in the study. Of these, 49 patients were diabetic and 57 hypertensive. Exclusion criteria were patients with rheumatic heart disease, mitral valve prolapse, previous myocardial infarction, intraventricular conduction disturbances, atrial fibrillation, atrial flutter, acute pulmonary edema, mitral regurgitation, pericardial effusion, right ventricular dilatation with tricuspid regurgitation and one contraindication to thrombolytic therapy.

\section{Reference Group}

Twenty-seven age-matched male subjects with normal coronary angiogram were included in the study to obtain normal standard values of TDI-derived variables and enable a distinction between normal or impaired TDI-derived variables.

\section{Thrombolytic Therapy}

One hundred and eight patients received intravenous streptokinase ( 1.5 million $\mathrm{U}$ over $60 \mathrm{~min}$ ) followed by heparin, and the patients with history of previous use of streptokinase were excluded. One hundred and twelve patients were treated with $100 \mathrm{mg}$ of rt-PA. Aspirin was given on admission to the coronary care unit at a daily dose of $100 \mathrm{mg}$.

\section{Transthoracic Echocardiography}

Echocardiography was performed within $3 \mathrm{~h}$ after thrombolytic therapy with the use of GE vivid 7 and a $3.5-\mathrm{MHz}$-phased array transducer. The left ventricle was divided into 17 segments for assessment of the myocardium as previously described [6]. The left ventricular segmental wall motion score index was calculated. The wall motion for each segment was graded as normokinesia: 1; hypokinesia: 2; akinesia: 3 and dyskinesia: 4 . The wall motion score index was calculated by summing the scores for each segment and dividing by the number of analyzed segments [7].

\section{TDI Pattern during Sinus Rhythm}

A normal pattern consists of 3 major signals: a single systolic signal (Sm) and two distinct signals in early (Em) and late (Am) diastole, timed by the onset of early inflow and atrial contraction, respectively. Sm, Em and Am were measured in centimeters per second, and $\mathrm{Em} / \mathrm{Am}$ is the ratio of the early to late diastolic phase as previously described [8]. At pulsed wave TDI, velocities of long axis wall motion were assessed in apical views during end expiratory apnea, with a sample volume of $5 \mathrm{~mm}$ positioned at the annulus of the mitral valve.

The peak TDI-derived velocities (Sm, Em and Am) were measured at 6 mitral annular sites corresponding to different regions of the left ventricle. The following measurements were taken: two-chamber view to detect velocities at two sites corresponding to the anterolateral and inferior regions, three-chamber view to detect velocities at two sites corresponding to the anterior septum and posterior regions and four-chamber view to detect velocities at two sites corresponding to the posterior septum and posterolateral regions. Infarct regions of the myocardial anterior septum and anterolateral regions were considered to belong to the perfusion territory of the left anterior descending artery (LAD). Noninfarct regions (study regions) included the posterior septum, inferior, posterior and posterolateral regions of the heart myocardium. Posterolateral and posterior regions were considered to belong to the perfusion territory of the circumflex coronary artery $(\mathrm{CX})$. Posterior septum and inferior region were regarded to perfuse the territory of the dominant right coronary artery (RCA) or dominant CX [9]. Two sites of each region were used to evaluate the TDI-derived variables: the lowest TDI-derived variable was selected as a single variable. The cut-off values of the TDIderived variables were calculated as median of reference group \pm 2 standard deviations (SD). Impaired TDI-derived variables were $\mathrm{Sm}$, Em velocities and Em/Am ratio less than the median of the reference group $+2 \mathrm{SD}$ and Am velocity more than the median of the reference group $-2 \mathrm{SD}$.

\section{Coronary Angiography}

Coronary cine angiography was performed for all patients in the study within one week after initiation of thrombolytic therapy. Coronary stenoses were quantified to detect the extent and severity of the coronary lesions and to detect the associated lesion with residual coronary stenosis. Luminal narrowing of $>50 \%$ was considered a hemodynamically significant coronary artery lesion.

\section{Statistical Analysis}

Continuous variables were summarized as mean \pm SD. A $p$ value $<0.05$ was considered statistically significant, and $<0.01$ was considered statistically highly significant. A stepwise multivariate regression model was used to identify the possible association of the independent variables and impaired TDI variables. Potential confounding of clinical variables (age, gender, diabetes mellitus, hypercholesterolemia, hypertension, coronary collaterals and residual infarct-related artery stenosis after thrombolysis, nitroglycerin IV infusion) were entered as independent variables.

The validity of the TDI-derived variables at the mitral valve annulus after acute myocardial infarction to detect the severity of coronary artery stenosis in the noninfarct region was assessed by estimating the predictive indices and $\kappa$ coefficient to determine the overall agreement with the data obtained from the coronary angiography. 
Fig. 1. a Correlation between coronary artery stenosis (independent variable) and Sm of TDI at mitral valve annulus corresponding to noninfarct region (dependent variable). b Correlation between coronary artery stenosis (independent variable) and diastolic Em/Am ratio of TDI at mitral valve annulus corresponding to noninfarct region (dependent variable).

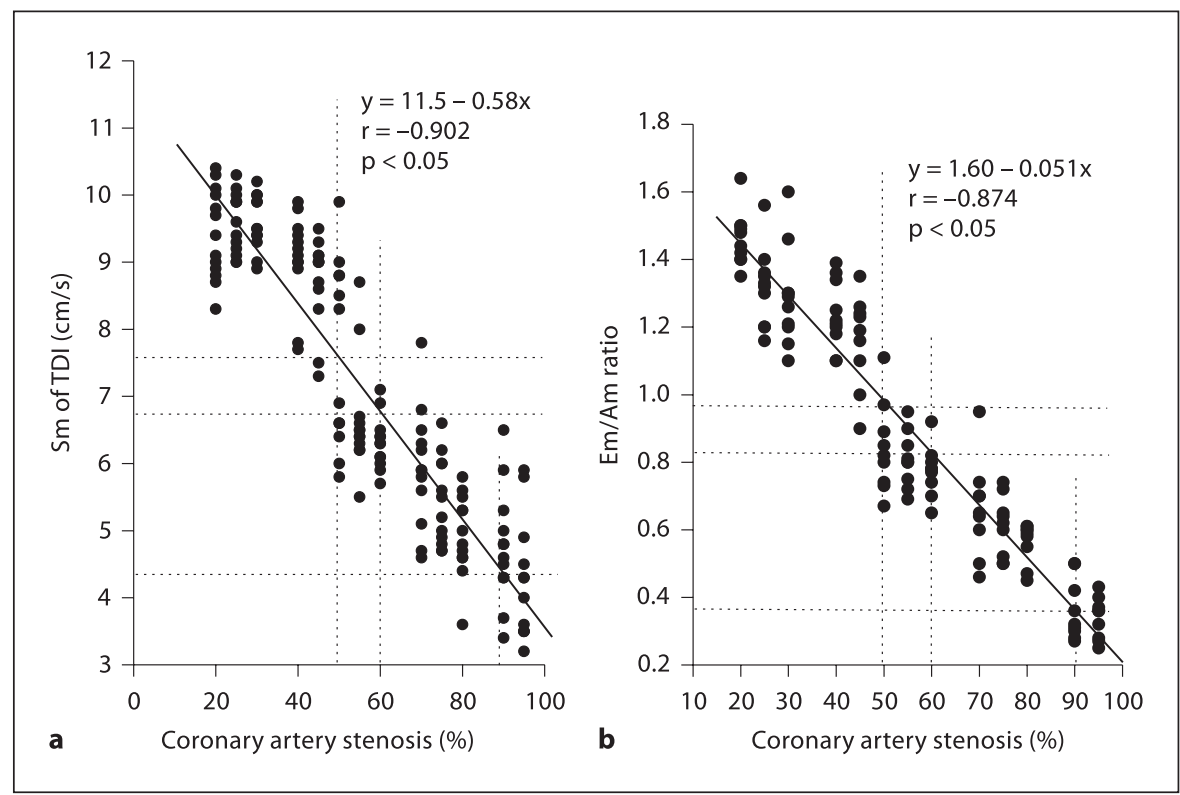

$\kappa=($ observed frequency of agreement - expected frequency of agreement)/(total observed - expected frequency of agreement).

Receiver-operating characteristic (ROC) curve (grade of sensitivity vs. false-positive) was used to identify the sensitivity and false-positive result of certain values of the variable with area under curve and probability of error with sensitivity $100 \%$ to detect the usefulness of the TDI-derived variables at the mitral valve annulus after acute myocardial infarction for prediction of the severity of coronary artery stenosis in the noninfarct region.

The agreement between measurements was determined according to the method of Bland and Altman [10] and expressed as the mean of the differences between two observations $\pm 2 \mathrm{SD}$ of the differences (coefficient of repeatability or variation). With low variability, the mean of the differences should approach zero, and the coefficient of variation should be small.

\section{Results}

\section{Coronary Angiography}

Of the 220 patients, 114 patients had a significant single proximal lesion in the LAD, and 106 patients had a significant lesion in the CX and/or RCA, of which had 68 LAD \& CX disease and 38 LAD and dominant RCA disease. There was a nonsignificant difference between patients with single-vessel disease and those with 2 -vessel disease with regards to the infarct-related artery residual stenosis: $60.52 \pm 5.12$ versus $65.29 \pm 4.76 \%$, respectively $(\mathrm{p}=0.41)$. Similarly, with regards to the noninfarct artery (study artery), there was no significant difference between patients with CX and those with RCA disease:
$60.16 \pm 6.04$ versus $55.00 \pm 4.96 \%$, respectively $(\mathrm{p}=$ $0.43)$. With regards to coronary collaterals, there was no significant difference between the patients with significant lesions in the CX artery compared with those with lesions in the dominant RCA: 23 (33.8\%) versus 10 $(26.3 \%)$, respectively $(\mathrm{p}=0.33)$.

\section{Echocardiography and Doppler Study}

Reference Group. The median TDI values ( $\pm \mathrm{SD}$ ) were $\mathrm{Sm}: 9.8 \pm 1.23 \mathrm{~cm} / \mathrm{s}, \mathrm{Em}: 11.63 \pm 1.14 \mathrm{~cm} / \mathrm{s}, \mathrm{Am}: 7.88 \pm$ $0.69 \mathrm{~cm} / \mathrm{s}$ and Em/Am ratio $=1.47 \pm 0.21$. The pulsedDoppler-derived mitral valve diastolic flow velocities indicated that the median value of E velocity was $158.41 \pm$ $23.12 \mathrm{~cm} / \mathrm{s}$ and that of Am was $89.58 \pm 21.35 \mathrm{~cm} / \mathrm{s}$, and hence the median value of $\mathrm{Em} / \mathrm{Am}$ ratio $=1.76 \pm 0.54$.

Study Group. The calculated cut-off value of Sm was $<7.37 \mathrm{~cm} / \mathrm{s}$ (<median - $2 \mathrm{SD})$, Em < $9.35 \mathrm{~cm} / \mathrm{s}$ (<median $-2 \mathrm{SD}), \mathrm{Am}>9.26 \mathrm{~cm} / \mathrm{s}(>$ median $+2 \mathrm{SD})$ and Em/ Am ratio 1.05 (<median - 2 SD).

There was a significant relationship between coronary artery stenosis (independent variable) and Sm and Em/ Am ratio of TDI at the mitral valve annulus corresponding to noninfarct region as dependent variable $(y=11.5-$ $0.05 \mathrm{x}, \mathrm{r}=-0.902, \mathrm{p}=0.028$ and $\mathrm{y}=1.87-0.14 \mathrm{x}, \mathrm{r}=$ $-0.754, \mathrm{p}=0.032$, respectively; fig. $1 \mathrm{a}, \mathrm{b})$.

With regards to the patients with single-vessel disease, the TDI-derived variables of Sm, Em and Em/Am ratio in the infarct region were significantly lower, while Am was significantly higher compared with the noninfarct region 
Table 1. Stepwise logistic multivariate analysis of patients with versus those without impaired TDI-derived Sm velocity in regards to age, gender, diabetes mellitus, hypercholesterolemia, infarct-related artery residual stenosis and coronary collaterals

\begin{tabular}{lllll}
\hline Independent variables & Coefficient & p value & OR & $95 \%$ CI \\
\hline Age & & & & \\
$\quad \begin{array}{l}\text { 5-year increment } \\
\quad \begin{array}{l}\text { 10-year increment } \\
\text { Gender }\end{array}\end{array}$ & 0.0217 & 0.451 & 0.542 & $0.425-1.191$ \\
$\quad$ Male & 0.2539 & 0.033 & 1.632 & $1.025-2.238$ \\
$\quad$ Female & 0.0215 & 0.241 & 0.871 & $0.362-1.407$ \\
$\begin{array}{l}\text { Diabetes mellitus } \\
\quad \text { Yes }\end{array}$ & 0.0341 & 0.122 & 0.612 & $0.217-1.436$ \\
$\quad$ No & 0.0629 & 0.124 & 0.799 & $0.424-1.238$ \\
$\begin{array}{l}\text { Hypercholesterolemia } \\
\quad \text { Yes }\end{array}$ & 0.0851 & 0.525 & 0.754 & $0.313-1.552$ \\
$\quad$ No & 0.0518 & 0.172 & 0.913 & $0.227-1.719$ \\
$\begin{array}{l}\text { IRA residual stenosis } \\
\quad<50 \%\end{array}$ & 0.0521 & 0.436 & 0.687 & $0.372-1.071$ \\
$\quad>50 \%$ & 0.0753 & 0.411 & 0.878 & $0.511-1.094$ \\
Coronary collaterals & 0.2057 & 0.035 & 1.773 & $1.045-2.619$ \\
$\quad$ Yes & & & & \\
$\quad$ No & 0.0351 & 0.114 & 0.995 & $0.372-1.618$ \\
\hline
\end{tabular}

$\mathrm{OR}=$ Odds ratio CI = confidence interval; IRA = infarct-related artery.
$(5.15 \pm 1.43$ vs. $10.84 \pm 0.61 \mathrm{~cm} / \mathrm{s}, \mathrm{p}=0.002 ; 5.76 \pm 1.53$ vs. $11.62 \pm 1.14 \mathrm{~cm} / \mathrm{s}, \mathrm{p}=0.003 ; 0.53 \pm 0.12$ vs. $1.47 \pm$ $1.32, \mathrm{p}=0.007$, and $12.58 \pm 1.95$ vs. $7.97 \pm 1.35, \mathrm{p}=0.04$, respectively). Also, with regards to the patients with 2vessel disease, the TDI-derived variables of Sm, Em and $\mathrm{Em} / \mathrm{Am}$ ratio in the infarct region were significantly lower, while Am was significantly higher compared with the noninfarct region $(5.15 \pm 1.43$ vs. $7.34 \pm 0.61 \mathrm{~cm} / \mathrm{s}, \mathrm{p}=$ $0.012 ; 5.76 \pm 1.53$ vs. $6.62 \pm 1.14 \mathrm{~cm} / \mathrm{s}, \mathrm{p}=0.022,0.43 \pm$ 0.12 vs. $0.69 \pm 0.32, \mathrm{p}=0.037$, and $12.58 \pm 1.95$ vs. 8.97 $\pm 1.35, \mathrm{p}=0.014$, respectively).

Regarding the noninfarct regions, there was an impaired TDI-derived variable in the posterolateral region in 48 patients, the posterior region in 32 patients, the inferior region in 16 patients and the posterior septum region in 8 patients.

The pulsed-Doppler-derived mitral valve diastolic flow velocities (Em, Am) and the ratio (Em/Am) showed that there was no significant difference in the diastolic function of the left ventricle between the patients with singlevessel and 2-vessel diseases $(81.82 \pm 10.2$ vs. $78.54 \pm 9.2$ $\mathrm{cm} / \mathrm{s}, \mathrm{p}=0.12 ; 119.8 \pm 11.5$ vs. $117.2 \pm 8.1 \mathrm{~cm} / \mathrm{s}, \mathrm{p}=0.29$, and $0.68 \pm 0.10$ vs. $0.67 \pm 0.08, \mathrm{p}=0.35$, respectively).

Forward Stepwise Logistic Analysis. Multivariate analysis revealed that impaired TDI-derived Sm and Em in the noninfarct region were significantly associated with the 10-year increment in the age of the patients $(\mathrm{OR}=$ $1.632, \mathrm{p}<0.033$, and $\mathrm{OR}=2.873, \mathrm{p}<0.021$, respectively), the infarct-related artery residual stenosis $>50 \%$ (OR $=$ $1.773, \mathrm{p}<0.035$, and $\mathrm{OR}=2.411, \mathrm{p}<0.019$, respectively) and the absence of coronary collaterals $(\mathrm{OR}=2.172$, $\mathrm{p}<$ 0.024 , and $\mathrm{OR}=2.972, \mathrm{p}<0.029$, respectively). However, there was no significant association with regards to gender (male/female), diabetes mellitus status (yes/no) and hypercholesterolemia (yes/no; tables 1,2).

Agreement and Reliability. $\mathrm{\kappa}$ indicated that there was an agreement between angiographically documented coronary artery disease and the TDI-derived variables $(\mathrm{Sm}$, Em, Am and Em/Am ratio) with $\kappa=0.775,0.731,0.693$ and 0.679 , respectively. The predictive indices showed that impaired systolic and diastolic velocities of TDI are valid for prediction of patients with significant coronary artery disease supplying the noninfarct region (table 3 ).

\section{ROC Curve}

The ideal cut-off values of Sm and Em velocities to predict significant coronary artery disease were $7.2 \mathrm{~cm} / \mathrm{s}$ and $6.4 \mathrm{~cm} / \mathrm{s}$. The positive likelihood ratios of $\mathrm{Sm}$ and $\mathrm{Em}$ variables were higher than other variables, and the negative likelihood ratios of Sm and Em variables were lower than other variables (table 4).

\section{Inter- and Intraobserver Variability}

Linear regression analysis revealed that there was excellent agreement between observers for the measurement of the TDI-derived variables of Sm, Em and Am 
Table 2. Stepwise logistic multivariate analysis of patients with versus those without impaired TDI-derived Em velocity in regards to age, gender, diabetes mellitus, hypercholesterolemia, infarct-related artery residual stenosis and coronary collaterals

\begin{tabular}{lllll}
\hline Independent variables & Coefficient & p value & OR & 95\% CI \\
\hline Age & & & & \\
$\quad \begin{array}{l}\text { 5-year increment } \\
\quad \text { 10-year increment }\end{array}$ & 0.0412 & 0.527 & 0.741 & $0.226-1.301$ \\
$\begin{array}{l}\text { Gender } \\
\quad \text { Male }\end{array}$ & 0.1858 & 0.021 & 2.873 & $1.245-4.917$ \\
$\quad$ Female & 0.0413 & 0.161 & 0.979 & $0.431-1.638$ \\
$\begin{array}{l}\text { Diabetes mellitus } \\
\quad \text { Yes }\end{array}$ & 0.0395 & 0.114 & 0.815 & $0.296-1.492$ \\
$\quad$ No & 0.0744 & 0.117 & 0.891 & $0.298-1.517$ \\
Hypercholesterolemia & 0.0791 & 0.213 & 0.806 & $0.396-1.358$ \\
$\quad$ Yes & 0.0662 & 0.141 & 0.985 & $0.307-1.414$ \\
$\quad$ No & 0.0593 & 0.224 & 0.867 & $0.279-1.475$ \\
IRA residual stenosis & & & & \\
$\quad<50 \%$ & 0.0858 & 0.217 & 0.972 & $0.405-1.396$ \\
$\quad>50 \%$ & 0.2134 & 0.019 & 2.411 & $1.025-4.191$ \\
Coronary collaterals & & & & \\
$\quad$ Yes & 0.0273 & 0.132 & 0.891 & $0.476-1.312$ \\
$\quad$ No & 0.2057 & 0.029 & 2.972 & $1.501-4.415$ \\
\hline$\quad$ OR = Odds ratio; CI $=$ confidence interval; IRA & & &
\end{tabular}

Table 3. Indices of TDI-derived variables for prediction of significant ( $>50 \%)$ coronary artery stenosis in the noninfarct region

\begin{tabular}{lccccccccc}
\hline Variables & TP & TN & FP & FN & Sensitivity, \% & Specificity, \% & Accuracy, \% & PPV, \% & NPV, \% \\
\hline Decreased Sm of TDI & 85 & 79 & 35 & 21 & 80.1 & 69.3 & 74.5 & 70.8 \\
Decreased Em of TDI & 82 & 76 & 38 & 24 & 77.3 & 66.6 & 71.8 & 68.3 & 76 \\
Increased Am of TDI & 80 & 74 & 40 & 26 & 75.5 & 64.9 & 70.0 & 66.6 & 74 \\
Decreased Em/Am ratio & 81 & 75 & 39 & 25 & 76.4 & 65.8 & 70.9 & 67.5 & 75 \\
\hline
\end{tabular}

FN = False-negative $; \mathrm{FP}=$ false-positive $\mathrm{NPV}=$ negative predictive value PPV = positive predictive value TN = true-negative $\mathrm{TP}=$ true-positive.

Table 4. ROC curve data to define the ideal cut-off values of the systolic and diastolic variables of TDI for prediction of significant coronary artery stenosis $(>50 \%)$ in the noninfarct region

\begin{tabular}{lllllll}
\hline Variables & $\begin{array}{l}\text { Ideal } \\
\text { cut-off } \\
\text { values }\end{array}$ & $\begin{array}{l}\text { Sensi- } \\
\text { tivity } \\
\%\end{array}$ & $\begin{array}{l}\text { Speci- } \\
\text { ficity } \\
\%\end{array}$ & $\begin{array}{l}\text { False- } \\
\text { positive } \\
\text { value, } \%\end{array}$ & $\begin{array}{l}\text { Positive } \\
\text { likelihood } \\
\text { ratio }\end{array}$ & $\begin{array}{l}\text { Negative } \\
\text { likelihood } \\
\text { ratio }\end{array}$ \\
\hline Sm velocity & $7.2 \mathrm{~cm} / \mathrm{s}$ & 87 & 82 & 18 & 4.83 & 0.158 \\
Em velocity & $6.4 \mathrm{~cm} / \mathrm{s}$ & 84 & 81 & 19 & 4.42 & 0.197 \\
Am velocity & $12.1 \mathrm{~cm} / \mathrm{s}$ & 74 & 72 & 28 & 2.64 & 0.361 \\
E/A ratio & 0.56 & 80 & 79 & 21 & 3.81 & 0.253 \\
\hline
\end{tabular}

The ideal cut-off value: high detection rate (sensitivity) with low false-positive value; false-positive value: 1 - specificity. 


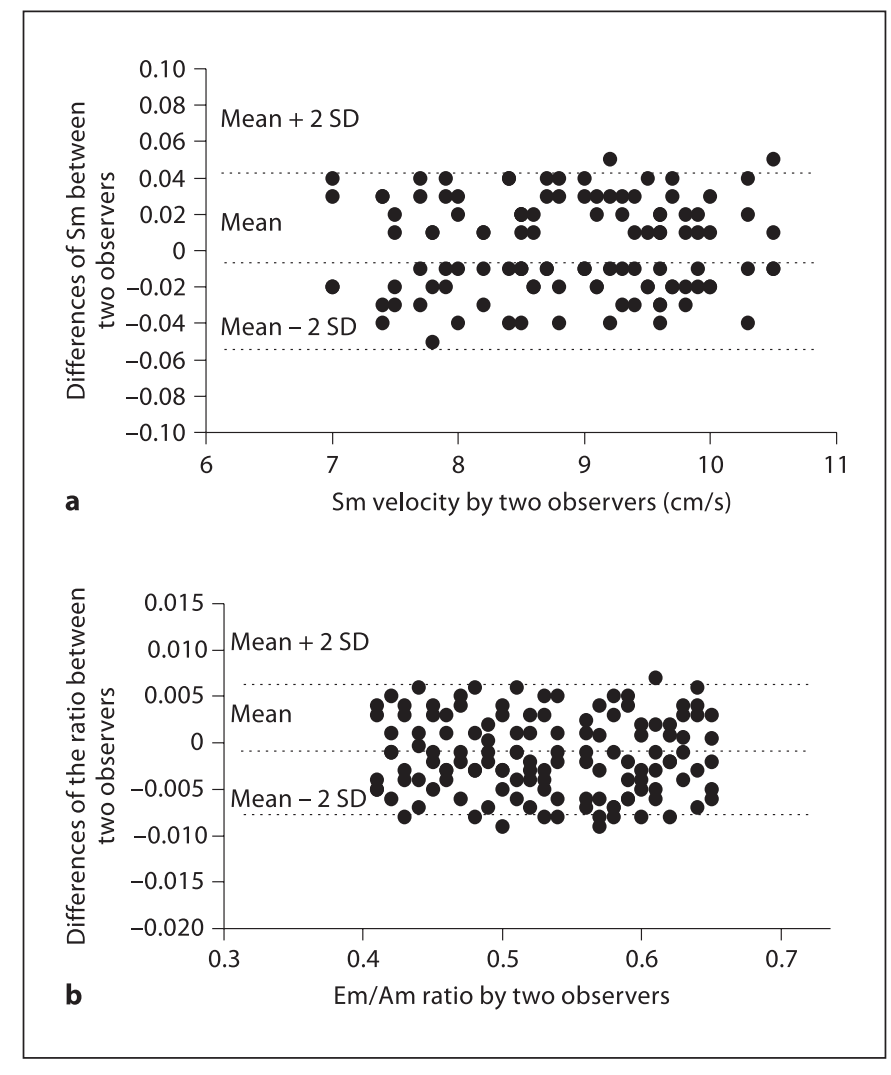

Fig. 2. a Plot of the mean values obtained by two observers on the $\mathrm{X}$ axis versus the difference of $\mathrm{Sm}$ values on the $\mathrm{Y}$ axis (bias \pm $2 \mathrm{SD}=-0.008 \pm 0.05 \mathrm{~cm} / \mathrm{s})$. $\mathbf{b}$ Plot of the mean values estimated by two observers on the $\mathrm{X}$ axis versus the difference of Em/Am ratio on the $\mathrm{Y}$ axis (bias $\pm 2 \mathrm{SD}=-0.001 \pm 0.007$ ).

$(\mathrm{r}=0.964, \mathrm{p}=0.008 ; \mathrm{r}=0.917, \mathrm{p}=0.007 ; \mathrm{r}=0.985, \mathrm{p}=$ 0.009 , respectively). Using the plot of Bland and Altman [10], there was good agreement between two observers; the bias $\pm 2 \mathrm{SD}$ of $\mathrm{Sm}$ was $-0.008 \pm 0.05 \mathrm{~cm} / \mathrm{s}$ (fig. $2 \mathrm{a}$ ), and the Em/Am ratio was $-0.001 \pm 0.007$ (fig. $2 b$ ). Using the plot of Bland and Altman [10] for the reproducibility of the TDI-derived variables of Sm, Em and Am, the bias $\pm 2 \mathrm{SD}$ was $-0.003 \pm 0.04 \mathrm{~cm} / \mathrm{s},-0.002 \pm 0.02 \mathrm{~cm} / \mathrm{s}$ and $-0.003 \pm 0.05 \mathrm{~cm} / \mathrm{s}$, respectively.

\section{Discussion}

The overall function of the left ventricle depends on a normal contraction of the longitudinal and circumferentially oriented myocardial fibers. Quantitation of the left ventricular function in the longitudinal axis may be clinically relevant, since the contraction in this direction is mainly due to subendocardial fibers. In case of ischemia, which specifically alters subendocardial layers, first abnormalities of wall motion will appear in the longitudinal axis. As the apex of the heart remains remarkably stationary, long axis changes are reflected in movements of the base of the heart $[11,12]$.

Myocardial ischemia alters regional contraction and relaxation. An acutely ischemic myocardium suffers not only from the loss of contractility but also tensile strength and stiffness. These alterations can be quantified by tissue velocity imaging. Derumeaux et al. [13] studied the patterns of tissue velocity profile during graded ischemia in an animal model to observe that ischemia resulted in rapid reduction of Sm and Em. There was a good correlation between decrease of $\mathrm{Sm}$ and regional myocardial flow. In another animal model, estimation of myocardial perfusion through myocardial velocities is valid in the situation of ongoing ischemia. In patients with chronic stable angina and normal ejection fraction, minor abnormalities of contraction and longitudinal shortening can be detected on TDI [14].

In this study, Sm is significantly dependent on the coronary artery stenosis. As the stenosis of the coronary artery in the noninfarct region increased, TDI-derived Sm in the noninfarct region decreased. Because myocyte contraction determines the regional systolic function, we found a significant inverse correlation between the coronary artery stenosis and TDI-derived Sm and Em. However, the TDI-derived Am in the noninfarct region had no significant correlation with the coronary artery disease. These observations support the active ventricular myocardium contribution to Sm and Em velocities and suggest that Am is perhaps reflective of passive ventricular motion or maybe more dependent on atrial myocardium function.

Regional function is dependent on the number of normally functioning myocytes and is reduced with myocyte necrosis and replacement fibrosis. Ischemia and hypoxia may alter systolic and diastolic myocardial function. Regional function is also dependent on the adrenergic nervous system and the circulating catecholamines, which play an important role in regulating the myocardial inotropic and lusitropic states at rest and with exercise [15]. Shan et al. [15] reported that systolic myocardial velocity and Em are strongly dependent on both the number of myocytes and the myocardial $\beta$-adrenergic receptor density. The $\beta$-adrenergic receptor stimulation results in a significant acceleration of isovolumetric relaxation through cAMP-dependent phosphorylation of phospholamban and troponin I [16]. Phospholamban phosphory- 
lation results in an increase in Ca-ATPase activity that pumps Ca into the sarcoplasmic reticulum, thus decreasing the amount of calcium at the contractile proteins. Phosphorylation of troponin I also aids relaxation, as it desensitizes the contractile proteins to calcium.

Smiseth et al. [17] concluded that TDI can be recommended for clinical use for diagnosis of coronary artery disease. Lin et al. [18] concluded that pulsed wave TDI technique provides objective quantitative information for identification of multivessel or left CX stenosis (>50\%) in patients with chest pain but without apparent wall motion abnormalities on echocardiography.

Limitations of the study include a relatively small number of patients, only one-center experience and only patients with anterior myocardial infarction. Patients with 3-vessel coronary artery disease and significant nondominant RCA disease were not included.

\section{Conclusion}

In spite of the limitations and confounders, the data show that TDI-derived variables are independent predictors which can be used to identify patients with significant stenosis of the coronary arteries supplying the noninfarct region, which may be helpful in considering these patients for coronary angiography in the early postinfarction period.

\section{References}

$>1$ Penicka M, Bartunek J, Wijins W, DeWolf I, Heyndrickx GR, DeReadt H, Barbato E: Tissue Doppler imaging predicts recovery of left ventricular function after recanalization of an occluded coronary artery. J Am Coll Cardiol 2004;43:85-91.

$>2$ Bountioukos M, Schinkel AF, Bax J, Rizzello V, Valkema R, Krenning BJ, Biagini E, Vourouri EC, Roelandt JRTC, Poldermans D: Pulsed wave tissue Doppler imaging for quantification of contractile reserve in stunned, hibernating and scarred myocardium. Heart 2004;90:506-510.

$>3$ Stengel SM, Allemann Y, Zimmerli M, Lipp E, Kucher N, Mohacsi P, Seiler C: Doppler tissue imaging for assessing left ventricular diastolic dysfunction in heart transplant rejection. Heart 2001;86:432-437.

4 McMahon MY, Nagueh SF, Pignatelli RH, Danfield SW, Dreyer WJ, Price JF, Clunie S, Bezold LI, Hays AL, Towbin JA, Eiden BW: Characterization of left ventricular function by tissue Doppler imaging and clinical status in children with hypertrophic cardiomyopathy. Circulation 2004;109:1756-1762.

5 Wang M, Yip GWK, Wang AYM, Zhang Y, Ho PY, Tse MK, Lam PKW, Sanderson JE: Peak early diastolic mitral annulus velocity by tissue Doppler imaging adds independent and incremental prognostic value. J Am Coll Cardiol 2003;41:820-826.
-6 Cerqueira MD, Weisman NJ, Dilsizian V, Jacobs AK, Kaul S, Laskey WK, Pennell DJ, Rumberger JA, Ryan T, Verani MS: Standardized myocardial segmentation and nomenclature for tomographic imaging of the heart: a statement for health care professionals from the cardiac imaging committee of the council on clinical cardiology of the American Heart Association. Circulation 2002;105:539-542

7 Otasevic P, Neskovic AN, Popovic Z, Vlahovic A, Bojic D, Bojic M, Popovic AD: Short early filling deceleration time on day 1 after acute myocardial infarction is associated with short- and long-term left ventricular remodeling. Heart 2001;85:527-532.

8 Penicka M, Bartunek J, DeBruyne B, Vanderheyden M, Goethals M, De Zutter M, Brugada $\mathrm{P}$, Geelen P: Improvement of left ventricular function after cardiac resynchronization therapy is predicted by tissue Doppler imaging echocardiography. Circulation 2004;109:978-983.

$>9$ Schiller NB, Acquatella H, Ports T, Drew D, Goerke J, Ringertz H, Silverman NH, Brundage B, Botvinick EH, Boswell R, Carlsson E, Parmley WW: Left ventricular volume from paired biplane two-dimensional echocardiography. Circulation 1979;60:547-555.

10 Bland JM, Altman DG: Statistical method for assessing agreement between two methods of clinical measurement. Lancet 1986; 1 : 307-310.

11 Rushmer RF, Crystal DK, Wagner C: The functional anatomy of ventricular contraction. Circ Res 1952;1:162-170.

12 Isaaz K: What are we actually measuring by Doppler tissue imaging? J Am Coll Cardiol 2000;36:897-899.
-13 Derumeaux G, Ovize M, Loufoua J, AndreFouet X, Minaire Y, Cribier A, Letac B: Doppler tissue imaging quantitates regional wall motion during myocardial ischemia and reperfusion. Circulation 1998;97:19701977.

14 Edvardsen T, Urheim S, Skulstad H, Stiene K, Ihlen H, Smiseth OA: Quantification of left ventricular systolic function by tissue Doppler echocardiography: added value of measuring pre- and postejection velocities in ischemic myocardium. Circulation 2002; 105:2071-2077.

-15 Shan K, Bick RJ, Poindexter BJ, Shimoni S, Lersou GV, Reardon MJ, Howell JF, Zoghbi WA, Nagueh SF: Relation of tissue Doppler derived myocardial velocities to myocardial structure and $\beta$-adrenergic receptor density in humans. J Am Coll Cardiol 2000;36:891896.

16 Parker JD, Landzberg JS, Bittel JA, Mirsky I, Colucci WS: Effects of $\beta$-adrenergic stimulation with dobutamine on isovolumic relaxation in the normal and failing human left ventricle. Circulation 1991;84:1040-1048.

17 Smiseth OA, Stoylen A, Ihlen H: Tissue Doppler imaging for the diagnosis of coronary artery disease. Curr Opin Cardiol 2004; 19:421-429.

18 Lin FC, Chang SH, Hsieh IC, Hung KC, Yeh SJ, See LC, Wu D: Time to peak velocity measurements by pulsed wave Doppler tissue imaging to quantify ischemia-related regional myocardial asynchrony. J Am Soc Echocardiogr 2004;17:299-306. 